\title{
Analysing Open Source Software in Terms of Its Characteristics and Establishing New Paradigms
}

\author{
Harmaninder J. S. Sidhu \\ Desh Bhagat University/Department of Computer Science, Mandi Gobindgarh, 147301, India. \\ E-mail: jeetsinder@gmail.com \\ Sawtantar S. Khurmi \\ Yadavindra College of Engineering, Talwandi Sabo, 151302, Bathinda, India. \\ E-mail: sawtantar@gmail.com
}

\begin{abstract}
The world that we see and in which we live is driven by open source platforms. Whether we talk about Linux and Apache or Drupal and Joomla (all are open source platforms), right from the beginning the open source technology has always been influencing. If we go online and try to find out open source link, we find that it is difficult to find a site/online application without an open source connection. This paper examines Free and Open Source Software (FOSS) in an empirical setup in terms of its major characteristics i.e. Deployability and Usability. These two characteristics of FOSS are extremely important from point of view of its comparison with proprietary software. The different attributes of FOSS were identified in the literature and were made part of the present study to carry out empirical analysis of FOSS. Apart from this a number of attributes were also included in this empirical study those were agreed upon by the participants while carrying out pilot study. This paper throws light on the experience of different kinds of users associated with FOSS. The statistical analysis using fisher's exact test was used to conclude the dependability of important characteristics of FOSS on each other.
\end{abstract}

Index Terms-Open source software (OSS)\Free and open source software (FOSS), FOSS Characteristics, FOSS Attributes, FOSS Empirical Study/Analysis, FOSS Deployability, FOSS Usability.

\section{INTRODUCTION}

Among different kinds of software that are available in the market two categories are such which seem to influence this world the most. These are known as open source and closed source software. Open Source Software (OSS) is also called Free and Open Source Software (FOSS) whereas closed source software is termed as proprietary software [1]. Open-Source Software is often developed in public collaborative manner in which emphasis is on global distribution of the software may be via the Internet. As far as the history of FOSS is concerned [2] the free software movement started in 1983. But, at that time also there existed some products i.e. software that exactly or almost fit the definition of FOSS. Those earlier projects provided the freedom to study, use, modi- fy and redistribute them but they were not the part of an organized movement to spread the practice, the philosophy or message of FOSS. The FOSS movement was launched by Richard Stallman [3]. The motive behind this movement was to make available the users with modifiable source code, because at that times it had become a trend to provide the users with the run-able version of the software by the developers thus stealing away the freedom of manipulating with the source code to develop a new software from the existing one by customizing it.

\section{A. Sketching the Background}

- The first attempt of open source sharing had nothing to do with software! [4]

It was in 1911 that Henry Ford, an innovative automaker became a driving force behind the launch of an association that was comprised of motor vehicle manufacturers. An open source initiative was initiated by this association in which the major US auto manufacturers came together to share technology patents openly without looking for any economic gains in return. It was the first open source sharing effort even before the first computer came into existence.

- The first open source software? [4]

It is a common belief that Linux is the first open source software of this world. But, in actual A-2 is the first open source system. It was developed in 1953 for UNIVAC compiler. After the development of this system the users were provided with the source code to make improvements to the present system and send feedback (at that time).

- The year, the term "open source" was coined?

It was in 1998 when the term "open source" was first introduced at the time of the release of Navigator's source code. Over the next few days it was heavily promoted. After it got approval from Linus Torvalds, the man behind the Linux, the term got worldwide recognition and since then it is popularly used in its present form. [4]

\section{B. Research Objectives}

The aim of this paper is to determine new (or modified) attributes of Free and Open Source Software (FOSS) and 
also to establish if it is possible to hypothesise the dependability of Deployability and Usability on each other. Determination of such an association is very important keeping in view the assessment of present status of FOSS in the software industry in India. It was also required to know the gender and age distribution of professionals involved in FOSS related issues, to identify education and income level of people actively participating in FOSS related activities and sources of information regarding FOSS.

The paper is organized as follows: Section I being the introduction. Section II mentions the details related to concepts involved in the present study that are existing in the literature under the title 'Related Work'. Section III briefly reveals the concepts related to FOSS (definition and licenses). Section IV presents the research approach employed to carry out this study thereby mentioning the tools used to carry out the analysis of primary data for interpretation of the results. Section V is concerned with the presentation of results supported by relevant figures and tables. Section VI draws the conclusion of the study also involving the limitations of the present study and its future scope.

\section{FREE AND OPEN SOURCE SOFTWARE}

FOSS may be termed as software which is accessible to everyone whosoever is in need of it [5]. The software (in operational form) along with its source code is available without any restraint to: use, copy, modify and redistribute. FOSS provides a user with numerous kinds of liberties i.e. liberty to: run the program, study the program in order to know the functionality of the program, software's redistribution (provided the software sticks to the first terms of license) and improve the program's functionality so that it may be released for public use. Such kind of liberty portrays FOSS design, adoption, development, and implementation [6].

\section{A. Definition}

Free and Open-source software is computer software with its source code made available with a license in which the copyright holder provides the rights to study, change and distribute the software to anyone and for any purpose [7].

The counterpart of FOSS is CSS (Closed Source Software). It is simply called proprietary software e.g. Microsoft Windows and MS-Office etc. It is not necessary for FOSS to be with zero price tag because the proprietary components and services may be charged for with monetary fees.

\section{B. Licenses}

The FOSS licence ensures that the software is free for all the users by ensuring your freedom to change and share the software [8].

There are three general categories [9] in which the open source software licenses may be grouped into as shown in Table 1.
Table 1. Types of software license

\begin{tabular}{|c|c|c|}
\hline License Type & Also known As & Examples \\
\hline Permissive & Academic & Apache, BSD, MIT \\
\hline Reciprocal & Copyleft & MPL, LGPL \\
\hline Propagating & Strong Copyleft & GPL, AGPL \\
\hline
\end{tabular}

\section{RELATED WORK}

There are two fundamental facts about Free and Open Source Software (FOSS) which influence its Usability considerably. First is that it can be said that number of users of a FOSS may be considered to be virtually boundless. Second is that it is the end user whose experience with the FOSS determines the software quality. These two factors make Usability an even more critical quality attribute for FOSS than it is for proprietary software. It is necessary to study the level of Usability of FOSS and the other related issues. This is because of the reason that there is a sharp increase in the use of FOSS projects by both individuals and organizations [10]. But, it is also true that the FOSS products are usually criticized for having little emphasis on Usability. FOSS developers are; no doubt, interested in Usability, but actually it is not their top priority. Hardly ever systematic Usability evaluation methods are employed in a FOSS project. Almost, all the efforts are common sense based. There is inadequate or very little understanding of Usability among most of the developers. Further, lack of resources and methods of evaluation make the situation even worse as reported by [11]. So, the limited distribution of FOSS is due to problems which are associated with Usability or the Usability itself which is often regarded as one of the main reasons behind this poor distribution. It is quite surprising that people involved in the development of FOSS or open source communities have managed to develop successfully a great deal of open source software [12]. It is the world which is dominated by proprietary software. Still, this remarkable achievement has been made. [13] Examines the current state of Usability in FOSS and tries to find out, why it is common to overlook Usability in Open Source Software? A popular Open Source Software called GNOME for desktop environment was used to provide just round the corner information for present structure for development and also to figure out the improvement areas. When test data was analysed it explored features of Usability and put forth possibility of investigation to enhance overall Usability within FOSS system. As far as the Deployability of FOSS is concerned it refers to the capability of software to be packaged for usage in a particular environment [14]. The various sub-characteristics and attributes of Deployability FOSS [14] are as follows. Portability: it signifies the capability of FOSS to be relocated from one system to another. It has following two attributes- (i) Software system independence (it indicates the extent to which the software is independent of the platform on which it is running such as operating system and other system/environment constraints i.e. type of programming language and the database system being used). (ii) Machine independence (it signifies the ease with which 
software can be run on any machine by making use of minimum possible resources like software, hardware, network etc.). Next is Installability: it is the ability of the FOSS to be installed as per the requirements of a specific environment. Its attribute(s) is/are- (i) Ease of installation (it refers to the effort required for installation of the software product/package in the production environment). Then comes the Configurability: it accounts for the ability to setup FOSS to run smoothly in a production environment. Its attribute(s) is/are- (i) Technical documentation (it refers to the simplicity with which the technical details of the software are listed in the user manual). After this we have Adapatability: it signifies the capability of FOSS to be moved to a new environment without the need of any additional action (i.e. an action which is not specified in the user manual). Its attribute(s) is/are- (i) Suitability for personalization (it is the ability of the software to be able to provide a particular user functionality to the user according to his/her experience). (ii) Adaptivity (it expresses the ability of the software to accommodate various requirements of different users). Last but not the least is Distributability: it refers to the capability of FOSS to run concurrently at different locations. Its attribute(s) is/are- (i) Distributed system (it represents the ease with which a system can be set up as distributed system).

\section{RESEARCH METHODOLOGY}

The basis of this research is an empirical study. Simple random sampling was used to collect the data to carry out this empirical research. Qualitative and quantitative methods were applied for data collection and data analysis respectively. The qualitative methods involved carrying out interviews and noting down the participants' observations. Quantitative methods were used to collect data by making use of questionnaire and that data was analyzed by making use of different Statistical methods/tools such as mean score, Coefficient of Variance, Cronbach's alpha and Fisher's exact test. A pilot study was also conducted before going for the actual research endeavour to modify the existing and identify new attributes of Usability namely Quick comprehension, Proficiency, Knowledge acquisition, Guidance/Help, Informative documentation, System support, Appealing manifestation, Well-responsive system, Dynamic functionality, Provided directivity, Reliance, Error control, Full user control, Satisfaction, General user support, Active feedback, User oriented, Consistent and clear screen display, User-friendly interface and Norms and standards. As identified through existing literature the Deployability of FOSS is made available by various quality models namely Boehm, IEEE, ISO 9126 and MCcall [15]. The Deployability of FOSS may be identified in terms of Portability, Installability, Configurability, Adaptability, and Distributability.

\section{RESULTS AND FINDINGS}

It is very important to know the status of professionals dealing with FOSS concerning their involvement in FOSS activities. An effort was made to know the standing of FOSS people involved in FOSS in one way or the other. Different FOSS users/people were enquired about their age, income and education level and their sources of information about FOSS. The research activity carried out revealed some interesting facts and figures which are discussed below.

\section{A. Gender and Age Distribution}

Two hundred people were the part of the survey of which seventy seven were females and one hundred and twenty three males. An effort has also been made to have people in the survey from different age groups. The selection of different age group was dictated by the fact that younger people are more tech savvy and expected to possess more knowledge regarding different types of software systems proprietary as well as FOSS. In all the survey out of two hundred people, 72 fall in the category of 20-30 and 124 between 31-40 and rest are above 40 (Fig. 1). Out of 122 males, 38 belong to the age group of 20-30 and 80 are in the age group of 31-40. Out of 78 females in the sample, 34 are from age group category 20-30 and 44 belong to $31-40$.

Out of total number of respondents the percentage of males and females falling in the category of 20-30 (age group) is nearly same (approximately 18 percent each). It is indicator of the present scenario that more and more young people irrespective of their gender are joining the FOSS community (Fig. 1).

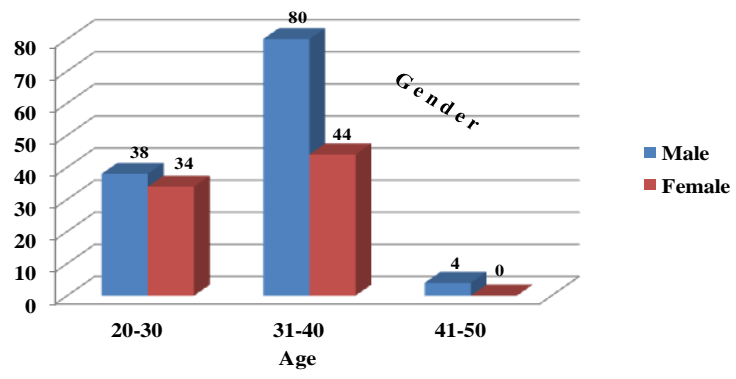

Fig.1. Sex and Age distribution of respondents

If we look at the figures we come to know that the scenario was comparatively different some time back (about a decade ago). As we can see that earlier the percentage of number of males joining the FOSS community was considerably high as compared to females. Data retrieved from the survey signifies that this percentage was approximately double in favour of males. This situation may be attributed to the likely fact that although the roots of FOSS are very deep in the history of software industry but it has gained popularity in the masses very quickly in the recent times in the country (i.e. India). Now, it won't be wrong to say that open source software industry is acting as an equal opportunity employer for both kind of sex and more and more number of females are developing confidence in open source industry. 
The percentage of respondents falling in the age group 41-50 is extremely low. This is another matter of concern. It sound very appealing if we say that about couple of decades back the open source industry had a very limited impact on Indian mind set. As the figures clearly signify that earlier the FOSS was not taken seriously (may be from career point of view) by most of the Indian software professionals. This may be because of the fact that as far as the free lancers were concerned (who are in software industry), they were not be able to see their future in FOSS and on the other hand the companies involved in the software activities were reluctant to pay their employees for getting involved in something that was or will be free of cost in the market. After all, business is for making money and getting profits to survive in this highly competitive world (in whatever field you are).

It is also apparent from the data that total no of female respondents when taken collectively from all the age groups contribute to more than fifty percent of the total number of male respondents falling in different categories of age groups. If we look at the overall figures we find out that the total number of female respondents is equal to 39 percent of total number of respondents in this field of open source technology. The figures clearly signify the substantial participation of females in this open source arena. The data also unfolds the truth that the awareness regarding the FOSS technologies in females is no less than that of males in this male dominating society (Fig. 1). It won't be wrong to say that if this trend continues then we are more likely to see a large number of professionals getting involved into this field of open source platforms in the country and also a greater level of confidence among the masses towards this sector of software industry.

The foregoing discussion proves that our sample is well representative in terms of age and sex distribution of FOSS users.

\section{B. Education and Income levels}

Different income groups were taken into consideration while choosing the respondents. Out of 200 sampled people 60 belong to the category of 4-6 lakh annual income while 132 are from the category of 6-8 lakh, rest of them belong to 8 lakh and above as shown in Fig. 2 .

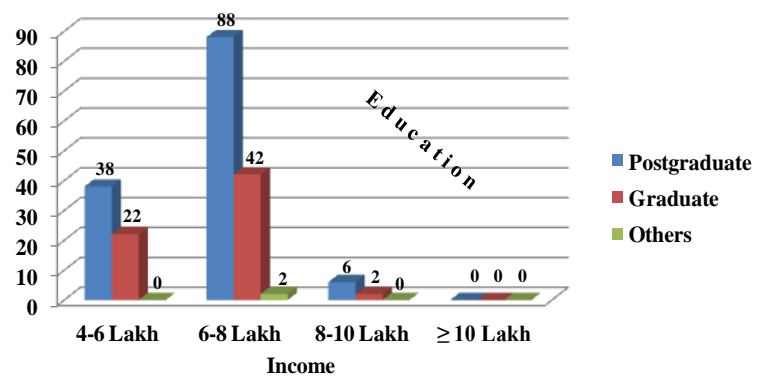

Fig.2. Education and Income level of the sampled people

The level of education which is an indicator of awareness regarding FOSS has also been taken into consideration in the form of Postgraduate, Graduate and other categories. The higher level of education in respondents may be inclined towards FOSS as compared to lower level of education. In our sample, out of 60 people belonging to 4-6 lakh income groups, 38 are postgraduates and 22 are graduates. Although the number of graduates is substantial in this case but still they are not comparable to that of number of postgraduates. It is also evident from the figures that it is hard to find people with lower level of education as far as their involvement in FOSS is concerned.

It is clear from the data depict in Fig. 2 that as we move from undergraduate level to the postgraduate level the number of responses keep on increasing (towards FOSS involvement) accordingly. This increase in number of respondents towards the higher education is quite high. It can also be interpreted that in case of first two categories of income groups the number of respondents in first category are nearly equal to (or less than) fifty percent of the number of respondents in the second category if we compare postgraduates and graduates in their respective disciplines. This inclination signifies that people might have started involving in the FOSS technologies quite earlier in the country keeping in view its importance and emergence in the Indian society as it is quite obvious that people with more experience are likely to earn more than compared to those with lesser experience unless you are exceptionally good in a particular field and are capable of giving tough competition to your highly experienced counterparts.

However, it can also be said that popularity of FOSS is not that old in the county as we can see from the last two categories of income that the number of respondents with still higher income are significantly small in number (Fig. 2 ). Whether it comes to graduate or postgraduate level the level of education does not affect the popularity of FOSS in earlier times (again on the basis of income based on experience). We draw a direct conclusion from this situation that earlier the people were reluctant to join FOSS industry or to work on FOSS technologies because they were not sure of having their future in this platform. Although the change in the scenario appears to be quite slow towards the adoption of FOSS as a feasible option, it can be said with certainty that the situation has changed at a very fast pace only some time back.

In case of extreme situations when we talk of the professionals with very low level of education or with reasonably high income group (Fig. 2) we find that there is extremely low probability of finding such people. Further, if we combine these two criteria together the situation becomes extremely unfavourable. Even taking each aspect one at a time we find it very difficult to cope up with the situation as the data clearly indicates that these two conditions are not fruitful to find a good number of professionals dealing with FOSS. The data also justifies the fact that maximum people can be found in higher education category or in second level of income group. So, every effort has been made to make the data representative in terms of education, income levels, gender, age, space and so on. 


\section{Information Sources for FOSS}

Though, people in our sample belong to educated category, even then the sources of information regarding FOSS need to be explored. The information or knowledge about FOSS which is disseminated by various sources is essential. We should be able to know the dominating information source for the people. This type of information about the source helps the authorities to promote that very particular source.

To know this fact, respondents were enquired about their source of information regarding BOSS and LINUX, such as internet, newspapers, magazines, radio/TV, colleagues, friends, conferences, workshops, academics, trainings and so on. It has been found that most of the information regarding FOSS technologies is provided by colleagues/friends, newspaper/magazines and internet. And this is almost same for both the categories of FOSS (i.e. BOSS and LINUX). Some weight-age has also been given to academics/trainings and conferences/workshops. The role of Radio/TV is negligible (Fig. 3). In the modern times electronic media like TV and internet is most popular source of entertainment. Therefore, such information should be spread through TV channels and internet so that people can have maximum access and can benefit from the FOSS.

If we look at the data (Fig. 3), we find that approximately 17 percent of the respondents agree that the very first source of information of FOSS for them was internet. This figure holds true for both FOSS operating systems (i.e. BOSS and Linux). Although this does not seems to be a promising figure as far as the popularity of internet is concerned in the present times still it is very appealing if we look at facts and figures about existence and progress of internet in India. In spite of lack of resources, high level of illiteracy rate and limited bandwidth, internet has been able to mark its presence as a promoter of general awareness about FOSS among various other sources of information dispersal.

It seems that the sources of information about FOSS such as help from friends and knowledge from magazines have outplayed other important sources of information which appear to be dominating at first instance (such as internet) as apparent from Fig. 3. But, a closer look at Indian market scenario (software and internet) reveals that it is not that surprising. Because, although FOSS and internet took birth much earlier in the history of software. But, still the commercialization of internet in India took quite a long time especially to reach far flung areas in the country. So, it is quite obvious that the other sources of information mentioned above helped in widespread diffusion of information about FOSS as they were already there much before the arrival of internet and even the FOSS itself.

Conferences and workshops are the indispensable part of education and research community. So, it is quite obvious that they contribute to knowledge distribution related to FOSS to a fairly good percentage (Fig. 3). If we look at combined contribution of Conferences, workshops and academics we find that they appear to be hold- ing an important position in this marathon as approximately more than one fourth of the total number of respondents considers them as the preliminary source of information in knowing about FOSS. The other sources for information retrieval have proved to be ineffective till date whatever the reasons may be however important they may appear to be. But, the times are changing, technologies are changing and so are the sources of information!

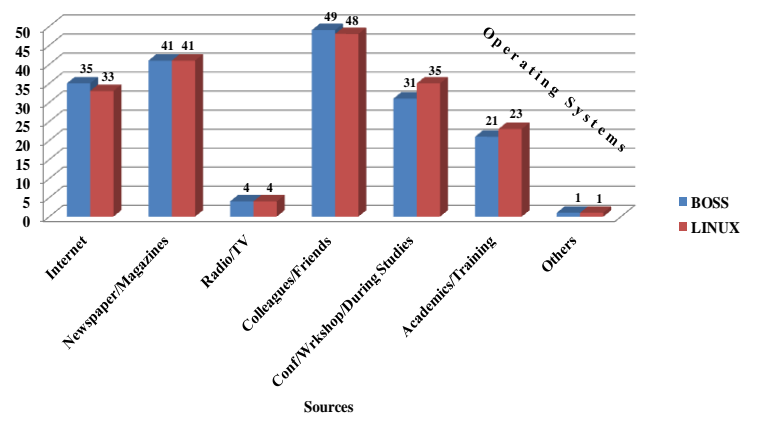

Fig.3. Sources of information regarding FOSS

\section{Reliability And Validity Of Data}

To find out the validity and reliability of the data achieved from this empirical endeavour the Cronbach's alpha test was carried out on the primary data. It helped in getting the estimation of internal consistency of the data collected. To be valid, the value of alpha is supposed to lie between 0 and 1 . Internal consistency indicates the degree to which all the data items are interrelated to one another while being subjected to a test. To ensure data's reliability it is very important to check its internal consistency beforehand.

The figures after subjecting the data to Cronbach's alpha test for Deployability and Usability are shown in Table 2 and Table 3 respectively.

Table 2. Cronbach's alpha for Deployability Data

\begin{tabular}{|c|c|c|}
\hline \multicolumn{3}{|c|}{ Reliability Statistics } \\
\hline $\begin{array}{c}\text { Cronbach's } \\
\text { Alpha }\end{array}$ & $\begin{array}{c}\text { N of } \\
\text { Items }\end{array}$ & VARIABLES \\
\hline 981 & 5 & $\begin{array}{c}\text { Portability, Installability, Con- } \\
\text { figurability, Adaptability, Dis- } \\
\text { tributability }\end{array}$ \\
\hline
\end{tabular}

Table 3. Cronbach's alpha for Usability Data

\begin{tabular}{|c|c|c|}
\hline \multicolumn{3}{|c|}{ Reliability Statistics } \\
\hline $\begin{array}{c}\text { Cronbach's } \\
\text { Alpha }\end{array}$ & $\begin{array}{c}\text { N of } \\
\text { Items }\end{array}$ & VARIABLES \\
\hline 690 & 6 & $\begin{array}{c}\text { Learnability, Understandability, } \\
\text { Operability, Attractiveness, Com- } \\
\text { plexity, Usability compliance }\end{array}$ \\
\hline
\end{tabular}

A value for Cronbach's alpha is considered to be acceptable if it comes out to be 0.7 or above. Therefore it is obvious from the two Cronbach's alpha values (i.e. 0.981 and 0.690 from Table 2 and Table 3 respectively.) that the data is sufficiently reliable and can be put to hypothesis testing. 


\section{E. Association Between Deployability \& Usability}

Deploybility (Deploybility with its attributes is graphically represented in Fig. 4) and Usability (Usability along with its proposed attributes is depicted in Fig. 5) are very important characteristics of a software especially when we are talking in terms of FOSS. The reason behind this view is that in case of proprietary software the user or the person acquiring the software gets full after sales support from the vendor. As far as its version, updates or other issues are concerned these are handled by the proprietor of the software product. So, user does not have to worry about the problems concerned with Deployability and Usability of the software product as it comes into market after passing through sufficiently reliable assessment levels carried out by persons responsible for its evolution. But, the scenario is considerably different when it comes to FOSS. Since, there is no proprietor as such so the development community is responsible for taking care regarding resolving issues if some problem arises at any point of time.

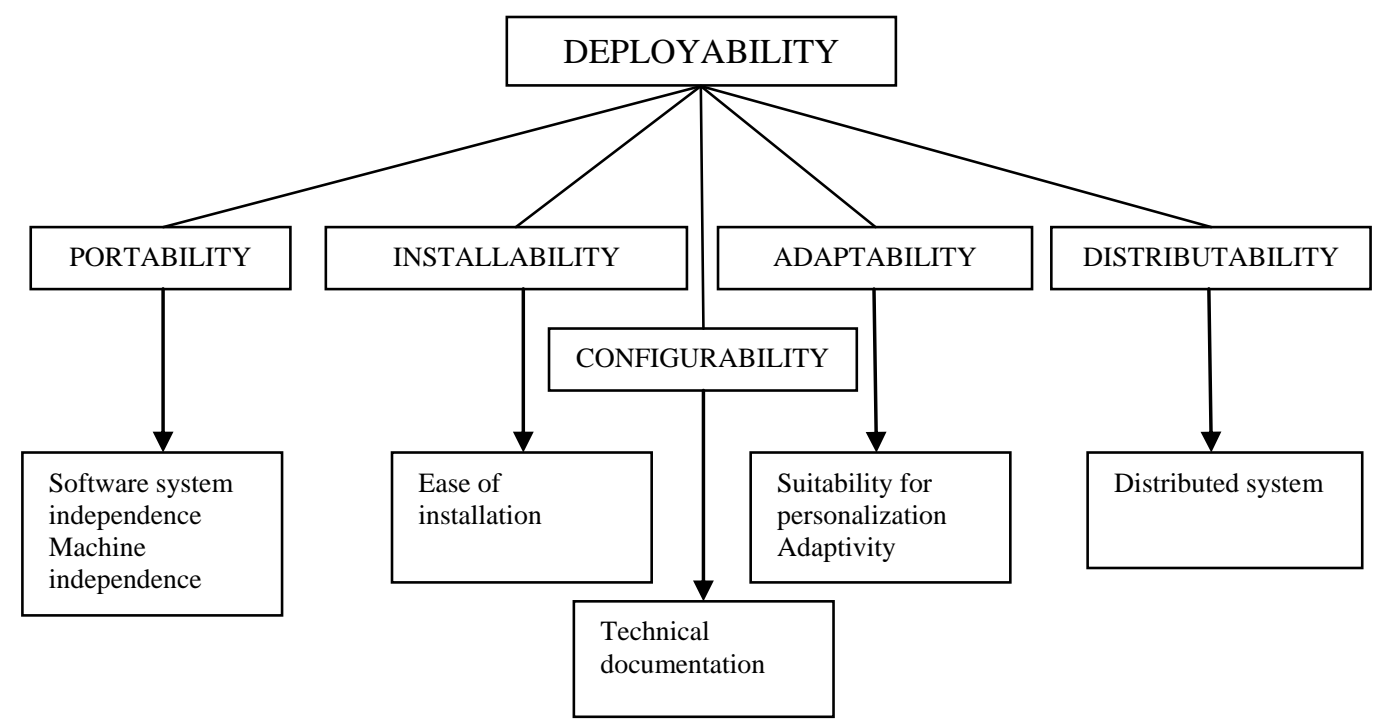

Fig.4. Graphical Representation Of Deployability

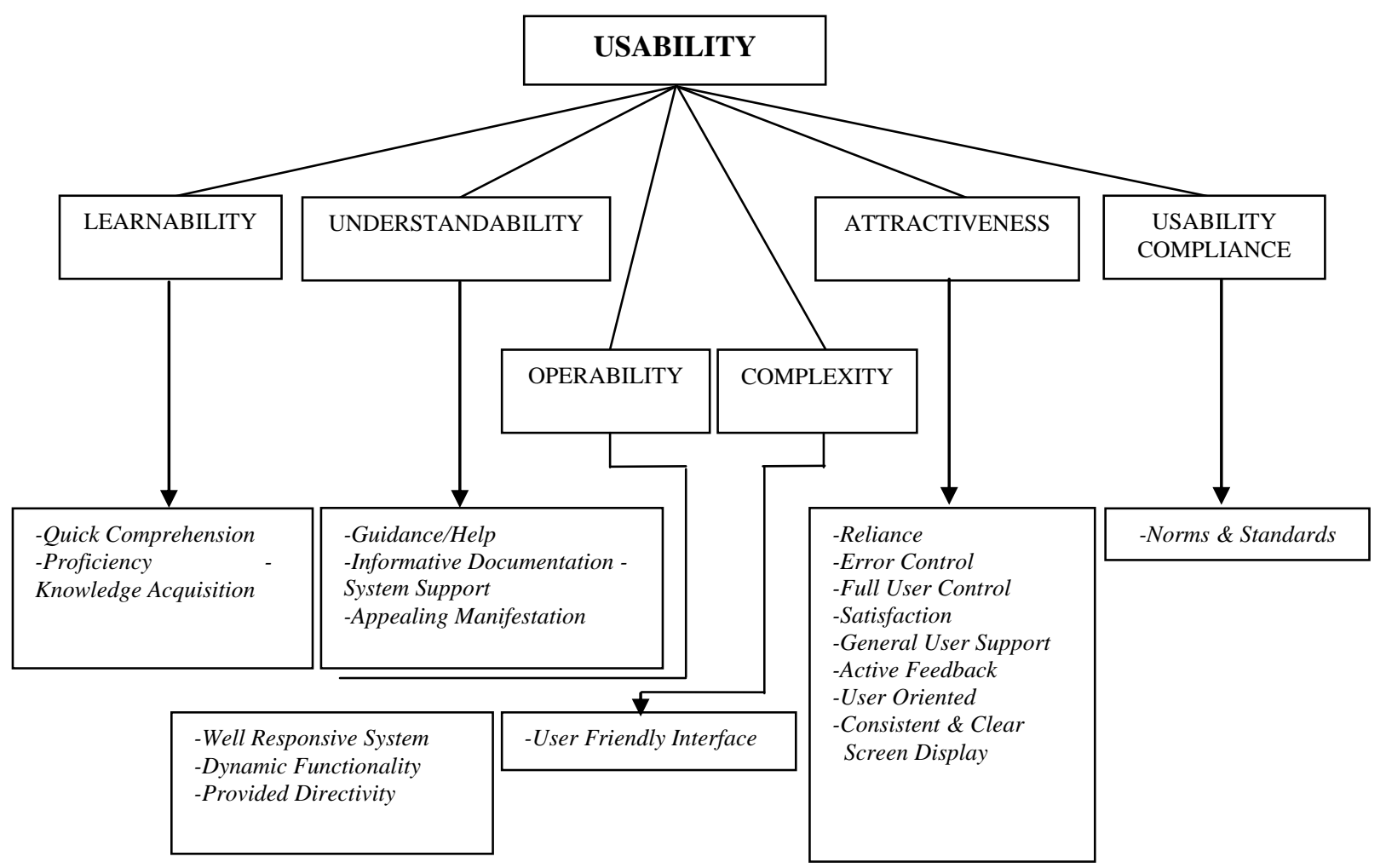

Fig.5. Usability Characteristic In Terms Of Its Sub-Characteristics \& Proposed Attributes 
It is therefore necessary to see how these two important characteristics of FOSS are related to each other. The association (Fig. 6) between these two characteristics has direct impact on the credibility of FOSS. This is because if any of the two characteristics is not able to live up to the expectations of the persons dealing with it then it will affect the functionality and the reliability of the other. Needless to say if software is not able to be deployed in heterogeneous environments then it is good for nothing. Clearly, its Usability in that case cannot be realized however useful it may be from the point of view of its working.

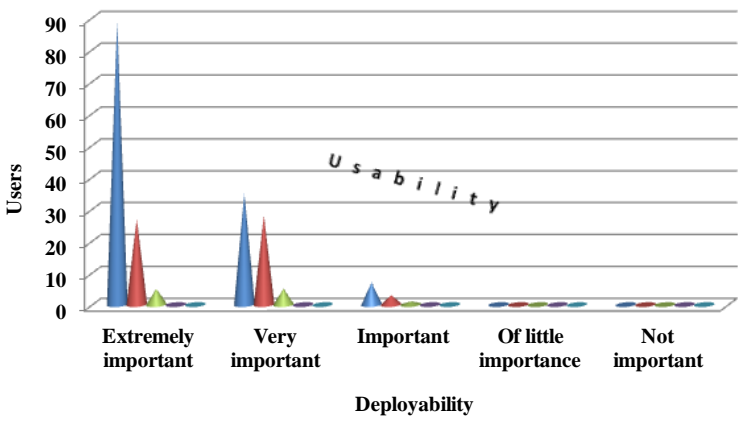

Fig.6. Association between Deployability and Usability

On the contrary if software is not doing as it was expected to be then its Deployability becomes questionable.

Table 4. SPSS output for Deployability \& Usability Crosstabultion

\begin{tabular}{|c|c|c|c|c|c|}
\hline \multicolumn{6}{|c|}{ Deploybility * Usability Crosstabulation } \\
\hline & \multicolumn{3}{c|}{ Usability } & \multirow{2}{*}{ Total } \\
\cline { 2 - 6 } \multicolumn{2}{|c|}{} & 1 & 2 & 3 & \\
\hline \multirow{3}{*}{ Deploybility } & 1 & 89 & 35 & 7 & 131 \\
\cline { 2 - 6 } & 2 & 27 & 28 & 3 & 58 \\
\cline { 2 - 5 } & 3 & 5 & 5 & 1 & 11 \\
\hline Total & 121 & 68 & 11 & 200 \\
\hline
\end{tabular}

Table 5. SPSS output for Fisher's Exact Test

\begin{tabular}{|c|c|c|c|c|c|}
\hline \multicolumn{7}{|c|}{ Chi-Square Tests } \\
\hline & Value & Df & $\begin{array}{c}\text { Asymptotic } \\
\text { Significance } \\
\text { (2-sided) }\end{array}$ & $\begin{array}{c}\text { Exact Sig. } \\
\text { (2-sided) }\end{array}$ & $\begin{array}{c}\text { Exact Sig. } \\
\text { (1-sided) }\end{array}$ \\
\hline $\begin{array}{c}\text { Pearson Chi- } \\
\text { Square }\end{array}$ & 9.694 & 4 & .046 & .048 & \\
\hline $\begin{array}{c}\text { Likelihood } \\
\text { Ratio }\end{array}$ & 9.526 & 4 & .049 & .058 & \\
\hline $\begin{array}{c}\text { Fisher's Ex- } \\
\text { act Test }\end{array}$ & 10.195 & & & .027 & \\
\hline $\begin{array}{c}\text { Linear-by- } \\
\text { Linear Asso- } \\
\text { ciation }\end{array}$ & 5.725 & 1 & .017 & .021 & .012 \\
\hline $\begin{array}{c}\text { N of Valid } \\
\text { Cases }\end{array}$ & 200 & & & & \\
\hline
\end{tabular}

This is because getting a software installed without having all the aspects incorporated in it does not make any sense from both user and developer point of view. Keeping in view the attributes of the two characteristics (Deploybility and Usability) the Fisher's Exact Test was used to check and hypothesize (See Table 4 \& 5) if there exists any relation between these two characteristics. The significant value of .027 (<.05), as evident from Table 5, clearly shows the validity of the alternate hypothesis that there certainly exist some association between the two characteristics of FOSS.

\section{F. Discussion}

The FOSS scenario is changing at a very fast pace. More and more young people are now turning towards FOSS community. Statistics show that the scenario was comparatively different some time back (about a decade ago). Although, the roots of FOSS are very deep in the history of software industry but it has gained popularity in the masses very quickly in the recent times in India. Now, it won't be wrong to say that open source software industry is acting as an equal opportunity employer for both kind of sex and more and more number of females is developing confidence in open source industry.

An important significance of the outcome of this research is that it is quite possible to consider that about some time back (approximately some two decades back or so) open source arena was not that influential in convincing the professionals involved in world of computer and especially software to get involved in the field of open source technologies. People were not able to see their future by getting involved in this field. It also signifies that whether we talk about individual software professionals or the software groups/companies/industries the statistics give us sufficient ground to think that it was hard for someone to believe at that time that open source community will flourish so much in such a short span of time especially when we know that the first open source attempt happened way back in 1953 (i.e. about 63 years ago).

Further, the level of education appears to be an indicator of awareness regarding FOSS. If we compare the level of education (i.e. higher and lower level) among people we find that higher level of education is more tending towards FOSS to that of lower level of education. As we move from undergraduate level to the postgraduate level the number of responses keeps on increasing (towards FOSS involvement) accordingly. This increase in number of people having the higher education is quite high as far as their FOSS involvement is concerned. Although, there appears to be considerable increase in FOSS popularity in a short span of time (as mentioned before) but from the earnings of the FOSS people it can also be concluded that people might have stepped towards open source platforms quite earlier in the country by recognizing its importance and keeping in view its magnitude and surfacing in the Indian software industry set up.

As far as the sources of information for FOSS are concerned, although, the internet is very important medium for information dissemination in the modern times, but surprisingly the statistics show that the people dependant on it as an information source for FOSS are not relatively that big in number. At the first look it appears that it is hard to believe in this finding. But, a vigilant look at the existing conditions in the past as well as in the present times related to internet and information technology reveals the fact that scarcity of resources and unavailability 
of higher bandwidth for substantially long period of time had restricted the adequate evolution of internet in India. Moreover, being a country with rural background there had been a lot of bottlenecks in the reach of internet in the far flung areas resulting in the delayed overall progress. But, on the whole it won't be wrong to say that in the modern times internet is going to take the lead. An important significance of this research's outcome is that various other sources of information dissemination like magazines (related to information technology and computers in general) and colleagues/friends have also got their place in this entire setup and this place is vital too if we look at the results of this empirical swot up. A crucial point that also needs to be discussed here is that in the coming times the scenario may be quite different because of the advent of new technologies (which keep on appearing one after the other and that has become a fashion in the IT industry).

\section{CONCLUSION}

FOSS is proving to be a promising alternative to its proprietary counterpart as increasing number of people are getting involved in it in one way or the other belonging to any age group or gender. It has also become a good source of income for the people involved in the software/hardware related activities through paid online or onsite training and support to open source products, paid software components for full functionality of a FOSS product, paid installation and training in case of complex FOSS, paid advertisements on FOSS running on mobile devices, paid special plug-ins for a FOSS product developed by an individual or a software company for a particular FOSS, hardware sales with preinstalled FOSS and a proprietary software tool/application to run on a FOSS. All these sources of income are attracting new generation towards FOSS world. Because of numerous sources for information propagation related to FOSS, there has been a significant increase in FOSS popularity. Also, it is worth saying that Deployability and Usability of FOSS go side by side and merits and demerits of one have favouring or adverse effect on other.

\section{A. Limitations}

The work done involves only two of the major characteristics of FOSS. This empirical research can be extended to involve other important characteristics of FOSS like Maintainability. Apart from this Deployability of FOSS may be viewed in terms of other relevant attributes related to FOSS, which need to be identified, if needed. Only the attributes of the considered characteristics (i.e. Deployability and Usability) were emphasised (in terms of the new one being proposed or existing one being modified), neither new sub-characteristics of the undertaken characteristics were identified nor the existing ones were modified (if needed). Limitations pertaining to this research study are mainly concerned with the bias factor which comes into play while taking down respondents' response. The level of biasness considerably affects the outcome of a research. This empirical research lacks the use of any method capable of handling fuzziness. An algorithm could be used to handle the biasness in the responses. The use of an algorithm/method capable of handling fuzziness and biasness significantly improves the reliability and accuracy of the results. It is easier to generalize the outcome of a research study in terms of the entire population if such methods are employed.

\section{B. Scope for Future Research}

As far as the future areas concerning this research are concerned, the other important characteristics namely Functionality, Efficiency and Reliability of FOSS can be taken into account. An empirical research can be carried out by identifying the appropriate sub-characteristics and attributes of these sub-characteristics of FOSS. It will help in attaining a complete insight into the present status of FOSS in the software industry. Moreover, appropriate methods capable of handling fuzziness and biasness in the feedback obtained from the people involved in FOSS can be used to have more practical results. This will help in complete exploration of FOSS.

\section{REFRENCES}

[1] Scacchi, W. (2013). Understanding open source software evolution [Online] Available: http://www.ics.uci.edu/ $\sim$ wscacchi/Papers/New/Understanding-OSS-

Evolution.pdf

[2] Bollier, D. (1999). The power of openness. Why citizens, education, government and business should care about the coming revolution in open source code software. Retrieved from http://www.opencode.org/h2o/

[3] $298 . \quad$ Vernudóttir, H. B. (2010). The Use of Free and Open Source Software by Icelandic Software Developers. Research report. B.Sc. Computer Science. Springler, New York.

[4] J. A. (2014, August 13). Red Crackle. Retrieved February 23, 2017, from http://redcrackle.com/blog/7-interestingfacts-about-open-source-software.

[5] S. J. (2010, January 6). Open Source, Open Development, Open Innovation Workshop. OSS Watch, 1, 3. Retrieved February 23, 2017, from http://oss-watch.ac.uk/ newsletters/january 2010 .

[6] Rothfuss, G. (2002). A framework for Open Source projects. Master Thesis in Computer Science, University of Zurich, Department of Information Technology.

[7] Laurent, A. M. S. (2008). Understanding Open Source and Free Software Licensing. O'Reilly Media. p. 4. ISBN 9780596553951.

[8] Lee, S. H. (1999). Open source software licensing. Available: cyber.law. harvard.edu/openlaw/ gpl.pdf.

[9] Alspaugh, T. A., Asuncion, H. U. and Scacchi, W. (2012). Software licenses, open source components, and open architectures. In: Aligning Enterprise, System, and Software Architectures (Eds. I. Mistr'1k, A. Tang, et al.,) IGI Global, pp 58-7.

[10] Raza, A. and Capretz, L. F. (2010). Contributors 'preference in open source software usability: an empirical study. International Journal of Software Engineering \& Applications, 1(2): 10-17.

[11] Andreasen, M. S., Nielsen, H. V., Schrøder, S. O. and Stage, J. (2006). Usability in open source software development: opinions and practice. Information technology and control. 35(3A).

[12] Nichols, D. M. and Twidale, M. B. (2003). The Usability 
of Open Source Software. First Monday. 8(1). Retrieved from http://firstmonday.org/issues/issue8_1/nichols/ index.html.

[13] Hall, J. (2014). Usability themes in open source software. In Scientific and Technical Communication (STC) Plan C.

[14] Sanga C. (2010). A technique for the evaluation of free and open source e-earning systems. Ph.D. Thesis, University of the Western Cape.

[15] Seffah, A., Kececi, N. and Donyaee, M. (2001). QUIM: A Framework for Quantifying Usability Metrics in Software Quality Models. Second Asia-Pacific Conference on Quality Software (APAQS'01). p. 0311.

\section{Authors' Profiles}

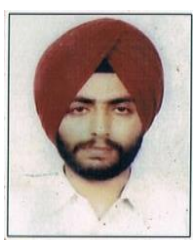

Harmaninder J. S. Sidhu is serving as Assistant Professor in Department of Computer Science and Applications, Desh Bhagat University, Mandi Gobindgarh, Punjab, India. He is involved in academic activities for last 9 years. His interest areas include Open Source Software and Algorithm Analysis.

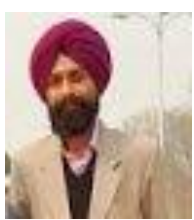

Sawtantar S. Khurmi is working with Yadavindra College of Engineering, Talwandi Sabo, Bathinda, Punjab, India. Earlier he has served as Prof. and Head, Dept. of Computer Science, Bhai Maha Singh College of Engg., Muktsar, Punjab, India He is involved in academic and research activities for last two decades. His interest areas include E- Governance and Cloud Computing.

How to cite this paper: Harmaninder J. S. Sidhu, Sawtantar S. Khurmi,"Analysing Open Source Software in Terms of Its Characteristics and Establishing New Paradigms", International Journal of Information Technology and Computer Science(IJITCS), Vol.9, No.7, pp.17-25, 2017. DOI: 10.5815/ijitcs.2017.07.02 